Please do not remove this page

RMIT

UNIVERSITY

\title{
A hybrid admission control scheme for wireless networks
}

Giang, Triet; Wang, Jidong

https://researchrepository.rmit.edu.au/esploro/outputs/9921861841701341/filesAndLinks?institution=61RMIT_INST\&index=null

Giang, T., \& Wang, J. (2005). A hybrid admission control scheme for wireless networks. Proceedings of the TENCON 2005 IEEE Region 10 Conference, 1-5. https://doi.org/10.1109/TENCON.2005.300853

Published Version: https://doi.org/10.1109/TENCON.2005.300853

Repository homepage: https://researchrepository.rmit.edu.au

(C) 2005 IEEE

Downloaded On 2023/04/26 12:10:39 +1000

Please do not remove this page 


\title{
A HYBRID ADMISSION CONTROL SCHEME FOR WIRELESS NETWORKS
}

\author{
Triet Giang, Jidong Wang \\ School of Electrical and Computer Engineering, RMIT University, Australia \\ Email: s3067460@rmit.edu.vn,jidong.wang@rmit.edu.au
}

\begin{abstract}
Threshold Access Sharing (TAS) is a policy based Call Admission Control (CAC) scheme in wireless IP networks. It has been shown to adapt well to the limited wireless resources. However, its handling of handoff calls is missing. In this paper, we proposed a hybrid scheme which combines an improved TAS scheme with a simplified rate-based borrowing scheme, aiming to improve its performance both on new call blocking and handoff call dropping probability. Our analysis and simulation have shown that the new scheme has met the expectation and its complexity is comparable to TAS.
\end{abstract}

\section{INTRODUCTION}

Wireless IP networks are undergoing rapid growth in recent years. More and more multimedia applications will be introduced to the wireless platform. Although they can tolerate certain traffic fluctuations in IP networks [1-3], a QoS infrastructure has to be deployed for the networks to provide satisfactory services. Admission control is an important component in the overall QoS mechanism. Due to the limit of network bandwidth resources, especially at the wireless admission point, IP networks cannot provide required satisfactory services when services are over admitted. Admission control's primary goal is to balance the network resource utilization and the service level provided.

From a network operator's point of view, the maximum utilization generally means more revenue and more profit. However, from customers' point of view, the quality of service is more concerned. Customers would like their service available most of the time. Also, customers would dislike the service being dropped by the network after admitted. In the case of wireless IP networks, it means low new call blocking probability and low handoff call dropping probability. Call Admission Control (CAC) is basically a decision making algorithm, which determines whether to admit or deny a service request, based on the current availability of the network resources.

In a cell based wireless IP network, service request to a cell can be classified into two categories: new calls and handoff calls (existing calls migrating from neighboring cells). In a simple CAC algorithm, new calls and handoff calls are admitted if there are enough resources to meet the QoS requirements of all ongoing calls as well as the new one. However, equal treatment of new calls and handoff calls is not always a good solution, because people would prefer waiting for admission rather than being dropped in the middle of their ser- vices. Among the published admission control algorithms [2, 4-6], Threshold Access Sharing (TAS) proposed by J. R. Moorman and J. W. Lockwood [7] is one of the best solutions. However, its ability to handle handoff call is not separated from new calls. The scheme also assumes that all services have fixed QoS requirement. Actually, the latest multimedia codecs can support multi-rate data rates, i.e. their QoS requirement can be scalable. Therefore, adaptive resource distribution can be considered. The Rate-Based Borrowing Scheme proposed by El-Kadi et al [4] is a good try on this line. We have introduced hybrid scheme based on TAS and rate-based borrowing scheme. Our scheme has addressed the priority of handoff call admission over the new call admission. The new scheme has been shown with improved performance in new call blocking probability and handoff call dropping probability.

The paper is organized as follows. Section 2 reviews the current TAS and the Rate-Based Borrowing. Section 3 suggests the Improved TAS and introduces the simplified version of the Rate-Based Borrowing. In Section 4, we analyze our model with simulation. Finally in Section 5, the conclusion is presented and further improvement of this model is discussed.

\section{THRESHOLD ACCESS SHARING AND RATE-BASED BORROWING}

Threshold access sharing and rate-based borrowing are two prominent schemes proposed for admission control. Our proposed solution is based on these two, which are summarized in the following.

\section{A. Threshold Access Sharing}

The Threshold Access Sharing (TAS) scheme proposed by J. R. Moorman and et al [7] is a typical policy based admission control for DiffServ architecture. It is simple and found to be the most effective of four main admission control policies (others are Equal Access Sharing, Equal Access Sharing with Reserve and Equal Access Sharing with Priority). In TAS, services are categorized into two classes. This widely adopted assumption is defined as:

- Class I is real-time traffic with high priority and delaysensitiveness, e.g. video, audio conferences or multimedia streaming applications. 
- Class II is non-real-time traffic, e.g. e-mail, web browsing or ftp services.

The utilization of the channel is divided into three levels, based on which, the admission decision takes place. The three levels are demonstrated in Figure 1.

\section{Utilization}

Capacity

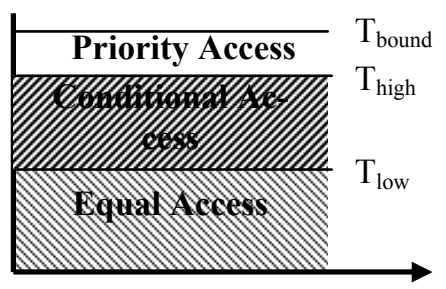

Figure 1: Threshold Access Sharing

- Equal Access: under $\mathrm{T}_{\text {low }}$ threshold: all calls are admitted equally as long as there is enough bandwidth

- Conditional Access: between $\mathrm{T}_{\text {low }}$ and $\mathrm{T}_{\text {high }}$ : Class II calls are admitted with the awareness that they may lose their connections or have their service reduced

- Priority Access: between $\mathrm{T}_{\text {high }}$ and $\mathrm{T}_{\text {bound }}$ : only Class I calls are admitted while some Class II calls have their service reduced or even dropped (to gain bandwidth Class I call admission)

- Above $\mathrm{T}_{\text {bound }}$ : all calls are rejected to maintain a stable system.

\section{B. Rate-Based Borrowing Scheme}

The Rate-Based Borrowing Scheme proposed by El-Kadi et al [2] is aimed to lower the handoff dropping probability by borrowing bandwidth from existing connections, in a fair way. In short, when requesting a service, the call specifies the desired bandwidth $(\mathrm{M})$ and the minimum acceptable bandwidth $(\mathrm{m})$. (The minimum acceptable bandwidth is the level of bandwidth below which the service would become unacceptable to a user). The scheme calculates the bandwidth loss tolerance (BLT):

$$
\mathrm{BLT}=\mathrm{M}-\mathrm{m}
$$

This is the amount of bandwidth which can be lent to other connections. Then the actual borrowable bandwidth of the connection is introduced, followed by the minimum expected bandwidth. The bandwidth borrowing and returning process happens in small increments (shares) of bandwidth so that the application can self-adjust accordingly. All calls "sacrifice" a number of shares to the new call. The shares are proportional to the bandwidth loss tolerance of the calls.

The scheme claimed to be fair by using two connection parameters, the adaptivity and the loss ratio. When calls finish and the system load is reduced, the system uses those parameters to return bandwidth to the original connection, where it was borrowed from. The scheme also claimed to have minimal computational overhead and no communication overhead.

\section{HYBRID SCHEME USING IMPROVED TAS AND SIMPLIFIED RATE-BASED BORROWING}

The TAS scheme offers a simple rule based admission control. Its missing of prioritization of handoff call admission is the biggest drawback. We have proposed a hybrid scheme, which combines an improved TAS, and a simplified ratebased bandwidth borrowing scheme. The new scheme addresses both new call admission and handoff call control.

\section{A. Improved TAS}

To prioritize handoff call admission, J. Hou and Y. Fang in [8] have made some review as follows. Most schemes fell into two main approaches:

- Guard Channel schemes: with some bandwidth is exclusively reserved for handoff.

- Queuing Priority schemes: when there is no bandwidth available, new calls are queued while handoff calls are blocked or new calls are blocked while handoff calls are queued or both are queued.

Using the first approach, we propose the following modifications to TAS. Based on the fact that it is better to block a new call than admit it and drop it in a short time later, the admission priority is defined as:

1. Class I handoff calls

2. Class II handoff calls

3. Class I new call requests

4. Class II new call requests

Next, we exclusively reserve a portion of bandwidth for handoff calls. The bandwidth utilization is divided into four levels as below.

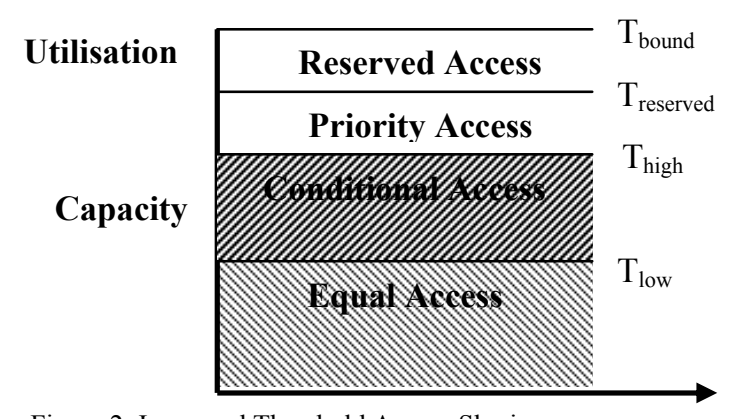

Figure 2: Improved Threshold Access Sharing

In short, we defined three levels of admission: 
- Fully admitted: calls are given desired bandwidth - as much as they request

- Conditionally admitted: calls are given desired bandwidth with awareness that their bandwidth may be reduced to minimum acceptable bandwidth

- Rejected: call requests are denied.

The improved TAS is then described as:

- Equal Access: all calls are fully admitted

- Conditional Access: Class I calls are fully admitted Class II calls are conditionally admitted

- Priority Access: Class II new calls are rejected. Other calls are conditionally admitted.

- Reserved Access: Handoff calls are conditionally admitted while new calls are rejected.

The advantages are:

- The handoff dropping probability is minimized as they can access to the reserved bandwidth

- Handoff calls are always admitted with the desired bandwidth even if they are conditionally admitted. This ensures software applications in the mobile terminal not to experience a sudden drop in bandwidth allowance.

- Once admitted, calls will never be dropped. It may be dropped if it is handed off to a congested neighbor cell.

It should be noted that:

- In a cell, no calls are forced to terminate, although they may have their services reduced in order to lend bandwidth to other calls.

- The system calculates the threshold values $\left(T_{\text {reserved, }}, T_{\text {high }}\right.$, $\mathrm{T}_{\text {low }}$ ) periodically and tries to return to the lower admission level to guarantee that it optimizes the resource.

To optimally utilize the reserved portion, we need to consider a scheme to control the usage.

\section{B. Simplified Rate-Based Borrowing Scheme}

We found that the parameters from the Rate-based borrowing schemes (ratio loss, adaptivity and minimum expected bandwidth) incurred more computational load but did not have much affect on the admission decision. The trade-off of the computational load (from the calculation of those parameters) and their purpose is not worth the effort. Therefore we ignored them and simplified the scheme.

We re-use some parameters from [2]: minimum acceptable bandwidth (m), desired bandwidth (M) and Bandwidth Loss Tolerance (BLT). This BLT amount is divided into s number of shares. Each bandwidth fraction which can be lent at a time in a cell is:

$$
\frac{B L T}{S}
$$

When receiving a call setup request and there isn't available bandwidth, the system will choose to reject it or borrow bandwidth from existing connections. Those connections will give up a fraction proportional to its BLT to give the application and the mobile terminal adjusts itself.

The bandwidth of a call that could be lent to another connection is:

$B_{\text {lending }}=\sum_{n=0}^{s} n * \frac{B L T}{s}$

where $\mathrm{n}$ is the lending level, which is the number of shares given away $(0 \leq \mathrm{n} \leq \mathrm{s})$. A high lending level means high bandwidth is taken, the call service highly suffers.

Once conditionally admitted (at desired bandwidth level), all calls are subject to have their services (bandwidth allowance) reduced. However they never have to give up bandwidth beyond the minimum acceptable level. The system takes bandwidth fractions from all conditionally admitted connections until there is enough bandwidth for the new connection.

The system has a database keeping the lending levels of all existing connections. Once the load is lessened, the system will return the free bandwidth to the most suffered connections i.e. ones with highest lending level. If all calls operate at desired bandwidth level, the free bandwidth is idle and waits for new calls.

\section{Hybrid Scheme}

The hybrid scheme based on the improved TAS and ratebased borrowing scheme is summarized in the following.

In the improved TAS, a fixed amount of bandwidth is reserved exclusively for Handoff calls. It works well with the Simplified Rate-Based Borrowing Scheme, which will guarantee a minimal handoff dropping probability.

Table I: THE ADMISSION POLICY IN THE HYBRID SCHEME

\begin{tabular}{|l|l|l|l|l|}
\hline & \multicolumn{2}{|c|}{ Class I } & \multicolumn{2}{c|}{ Class II } \\
\hline \multicolumn{1}{|c|}{ Access } & \multicolumn{1}{c|}{ Handoff } & \multicolumn{1}{c|}{ New } & Handoff & \multicolumn{1}{c|}{ New } \\
\hline Equal & Full & Full & Full & Full \\
\hline onditional & Full & Full & Conditional & Coditional \\
\hline Priority & Conditional & Conditional & Conditional & Rejected \\
\hline Reserved & Conditional & Rejected & Conditional & Rejected \\
\hline
\end{tabular}

The scheme defines some admission policies to priorities handoff calls over new calls, Class I calls over Class II calls. It guarantees that no calls are forced to terminate although they may have their service reduced. The service reduction process is transparent to the users. The computation is done at 
the base station; hence very limited functions are required in mobile terminals.

\section{SIMULATION}

The pre-eminence of the improved TAS with a simplified rate-based borrowing scheme is demonstrated as below. We set up a common environment for a cellular network simulation with two traffic classes and two call generators: one for new call requests and one for handoff calls. The total bandwidth in a cell is 90 bandwidth units. The bandwidth loss tolerance and the maximum lending level are 5 units of bandwidth. With the assumption that Class I calls are $20 \%$ of the total calls, handoff calls are also $20 \%$ as well.

We compare the outcome of this scheme with the Erlang B formula, shown in Figure 3.

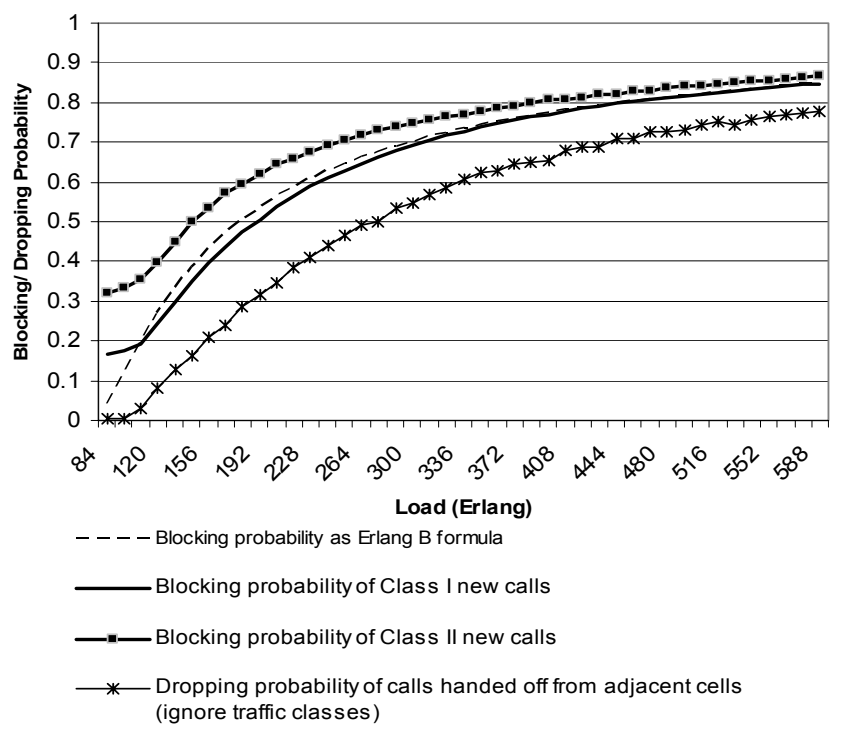

Figure 3: Blocking/ Dropping Probability of Hybrid scheme

The result is as predicted. Comparing to the normal situation (with Erlang B formula) we found that:

- It is harder to make a new Class II call while making a new Class I call is as normal

- Calls from adjacent cells handed off to this cell are admitted easier

In the same program run, we obtained data in Figure 4 and found the following:

- In a high load system, the number of calls conditionally admitted is less because more calls are dropped

- Handoff calls are less affected in high load situations than new calls.

Figure 5 and 6 show the distribution of admitted handoff and new calls.

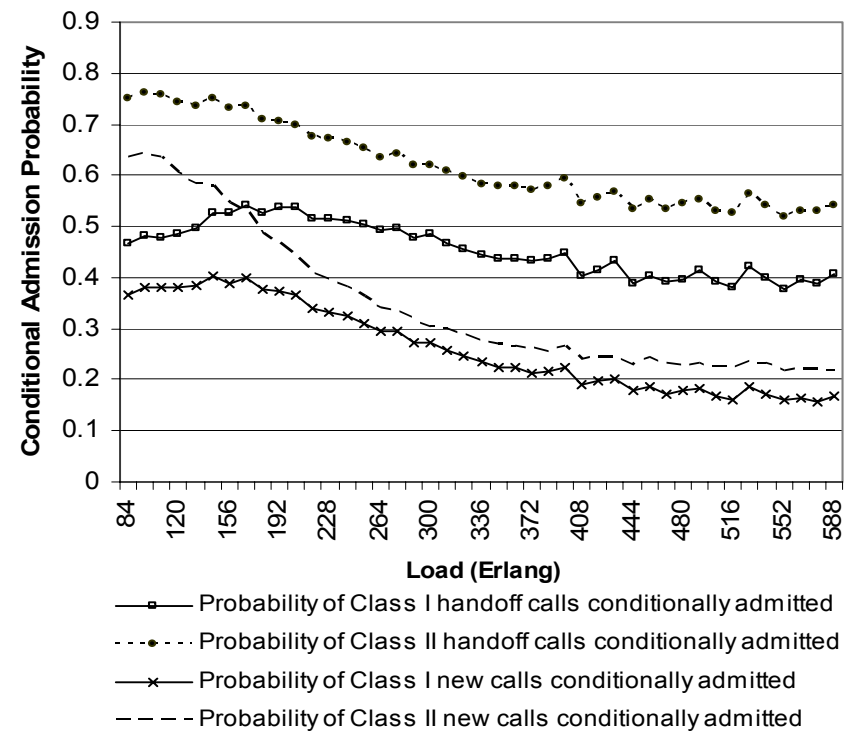

Figure 4: Probability of conditionally admitted calls

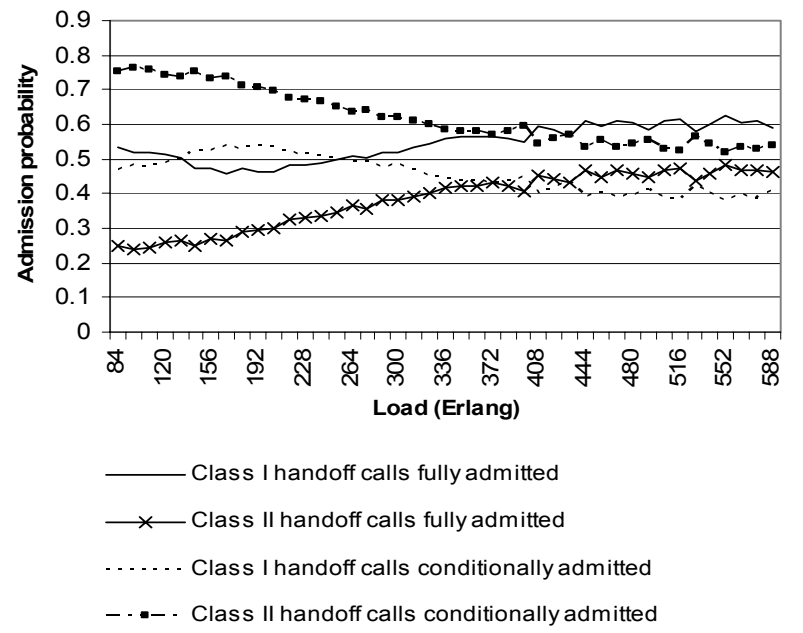

Figure 5: Performance on admitting handoff calls

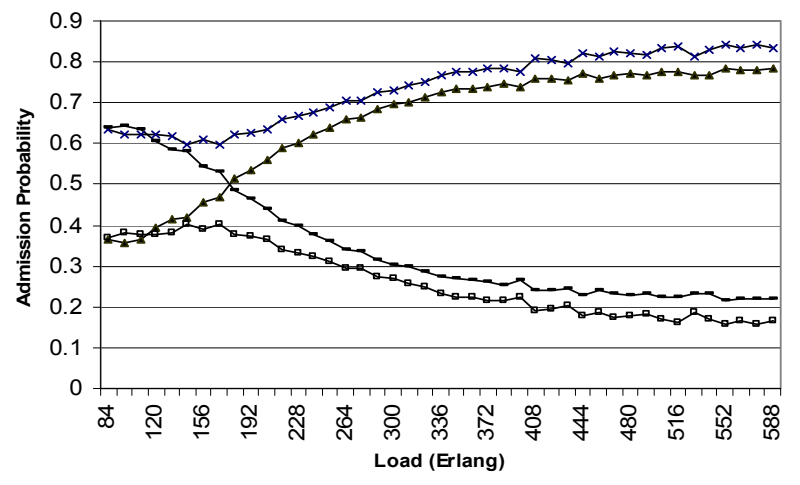

× Class I new calls fully admitted

$\rightarrow$ Class II new calls fully admitted

$\rightarrow$ Class I new calls conditionally admitted

_ Class II new calls conditionally admitted

Figure 6: Performance on admitting new calls 
- For handoff calls, regardless the system load, about $50 \%$ Class I calls are fully admitted while more Class II calls are fully admitted as the load gets higher

- For new calls, as the load increases, if calls can be admitted, most of them are fully admitted.

\section{CONCLUSION}

To address the priority of handoff calls and efficient resource utilization in wireless IP networks, we have proposed a hybrid scheme aiming to lower handoff call dropping probability and to maximize the resource utilization. The scheme overcomes the disadvantages of the original TAS and Ratebased borrowing schemes. It works on the basis of reserving a fixed amount of bandwidth for handoff calls. To gain more bandwidth to admit those prioritized calls, the system can "borrow" bandwidth from other calls. Our simulation has shown that the new scheme has outperformed the original TAS and it is simpler than the original rate borrowing scheme.

The scheme can be applied to the domain based wireless IP network, in which a number of cells can be grouped into a cluster. To further improve the handoff dropping probability, movement prediction can be considered. With movement awareness of calls in neighboring cells available, proper channel reservation can be adjusted to further reduce the chance of handoff call dropping. The scheme proposed can also be expanded to general cellular networks.

\section{REFERENCES}

1. Acampora, A.S. and M. Naghshineh, Control and Quality-of-Service provisioning in high-speed microcellular networks. IEEE Personal Communications, 1994: p. 36-43.

2. El-Kadi, M. and S. Olariu, A Rate-Based Borrowing Scheme for QoS Provisioning in Multimedia Wireless Networks. IEEE Transactions on Parallel and Distributed Systems, 2002. 13(2): p. 156-166.

3. Oliveira, C., J.B. Kim, and T. Suda, An Adaptive Congestion Control Scheme for High Speed Multimedia Wireless Networks. IEEE Journal Selected Areas in Communications, 1996. 16: p. 858-874.

4. Moorman, J.R. and J.W. Lockwood. Real-time Prioritized CAC in a Base Station Scheduler. in IEEE/ ACM Wowmom. 2000. Boston.

5. Acampora, A.S. and M. Naghshineh. QoS Provisioning in Micro-Cellular Networks Supporting Multimedia Traffic. in IEEE INFOCOM. 1995.

6. Peha, J.M. and A. Sutivong, Admission Control Algorithms for Cellular Systems. Wireless Networks, 2001. 7: p. 117-125.

7. Moorman, J.R. and J.W. Lockwood, Wireless call admission control using threshold access sharing.
Global Telecommunications Conference, 2001. GLOBECOM '01. IEEE, 2001. 6: p. 3698 - 3703.

8. Hou, J. and Y. Fang, Mobility-based call admission control schemes for wireless mobile networks. Wireless Communications and Mobile Computing, 2001. 1: p. 269-282. 